\title{
APRESENTAÇÃO SOBRE A TRADUÇÃO DE LIVROS INFANTIS E JUVENIS
}

Há muito tempo considerado um gênero "menor", a tradução da literatura infantil e juvenil vem ganhando cada vez mais espaço e prestígio como área de pesquisa acadêmica. Além do número crescente de publicações na área, prêmios de melhor tradução para crianças e jovens existem hoje tanto a nível internacional (Prêmio Hans Christian Andersen concedido pelo International Board on Books for Young People - IBBY) quanto a nível nacional (Prêmio Jabuti concedido pela Câmara Brasileira do Livro - CBL e pela Fundação Nacional do Livro Infantil e Juvenil - FNLIJ), o que de certa forma confirma essa situação bastante positiva da Tradução de Literatura Infantil e Juvenil como área consolidada, principalmente, no contexto dos Estudos da Tradução.

A tradução de livros para crianças e jovens sempre foi uma constante no Brasil, se lembrarmos que os títulos publicados na última década do século XIX pelo livreiro-editor Pedro da Silva Quaresma, na Coleção Biblioteca Infantil da Livraria do Povo, eram em sua grande maioria traduções dos contos europeus, configurados nos livros Histórias da Avozinha, Contos da Carochinha, Histórias da Baratinha, entre outros pelas mãos do jornalista Figueiredo Pimentel. O primeiro título aqui mencionado (terceiro volume da coleção), composto de várias narrativas curtas, segundo o editor era o mais bem aceito pelas crianças, pais, professores e imprensa, pois ali "se encontram os mais célebres contos, dos que andavam apenas na tradição oral, e outros traduzidos de vários autores especialistas do assunto" (prefácio da nova edição, 1959, p.6). Coube a Carlos Jansen a tradução de narrativas mais longas, como Contos seletos das mil e uma noites, Robinson Crusoé, Viagens de Gulliver, entre outros. (LAJOLO; ZILBERMAN, 1987, p. 29). 
O escritor Monteiro Lobato ao iniciar a sua atividade escrita para crianças, na década de 1920, inicia também o exercício tradutório para este público e traz para o cenário brasileiro a tradução de Alice no país das Maravilhas, de Lewis Carrol, Pinóquio, de Collodi entre outros títulos que até então circulavam somente na língua mãe.

Na década de 1940, Lourenço Filho avaliava que $70 \%$ da produção literária destinada à criança brasileira consistia de traduções de textos estrangeiros, preocupação gerada pela invisibilidade de uma produção nacional que circulava em torno de meia dúzia de autores, o que persiste até a década de 1970. No final da década de 1970, esse quadro começa a se modificar lentamente, e o mercado editorial brasileiro vai se alargar com a produção nacional, em particular pela Lei № 5692 de 11 de agosto de 1971, que fixava as diretrizes e bases para o Ensino de $1^{\circ}$ e $2^{\circ}$.

Atualmente não temos pesquisas quantitativas que tragam a porcentagem de livros traduzidos para crianças e jovens, em levantamento realizado por Verdolini, constata-se que as informações se encontram em materiais de estrangeiros (jornalistas e pesquisadores), como a jornalista Felicity Claire que "relata sua visita à Bienal do Livro no Rio de Janeiro em 2009, e afirma que em 2008 o número de obras traduzidas foi de $12 \%$ da quantidade total de livros publicados no Brasil (6.226 títulos de um total de 51.129)" (apud VERDOLINI, 2015, p.8).

Os números, ou a falta desses, parecem justificar as linhas e projetos de pesquisas na área. Alguns questionamentos prévios orientaram este número dedicado à literatura infantil e juvenil. Por exemplo, quais seriam os problemas específicos do tradutor de literatura infantil e juvenil? É possível falar neste caso de tradução ou trata-se de processos como adaptação, transposição livre ou reescritura? Qual seria o impacto desses processos na cultura de chegada? Segundo Daniela Bunn (2011, p. 103-111) A Fundação Nacional do Livro Infantil e Juvenil (FNLIJ), por exemplo, como lembra a tradutora, fundiu numa só categoria as premiações de tradução e adaptação, entendendo que não se pode estabelecer a priori fronteiras rígidas entre uma e outra. 
Um dos caminhos possíveis pode ser o de refletir sobre como levar a bagagem cultural, a cor local, a estranheza do original para a língua/cultura de acolhimento, sem assustar ou intimidar o jovem leitor da cultura de chegada? Ou ainda que soluções podem ser consideradas para obter uma tradução que cumpra seu papel dentro do contexto de produção e recepção a que se destina?

O próprio conceito de literatura infantil e juvenil não tem consensoentre os teóricos e é discutido neste número. Riitta Oittinen (2000), por exemplo, considera que a literatura infantil e juvenil é aquela literatura escrita e produzida para jovens e crianças ou lida por eles. Já Göte Klingberg (1986), por exemplo, declara que a literatura infantil e juvenil concerne somente àquela produzida para as crianças e jovens.

Desta forma, este volume temático de Cadernos de Tradução explora várias das perspectivas teórico-metodológicas que a Tradução da Literatura Infantil e Juvenil tem a nos oferecer. Através de seus dez artigos, um artigo traduzido, duas resenhas e uma entrevista, este númerp apresenta algumas das inúmeras questões controversas relacionadas a uma área de pesquisa aparentemente simples, mas ao mesmo tempo tão sensível e complexa.

No primeiro artigo, "Contos de Grimm e novos contos de Grimm: tradução e adaptação em Monteiro Lobato”, Sylvia Maria Trusen busca apresentar as contradições de Monteiro Lobato, sua luta pela emancipação da literatura infantil dos moldes europeus, e o seu papel de tradutor de obras estrangeiras para o ambiente nacional.

Já o segundo artigo, "Com Palavras Minhas: A Tradução de Verbos de Elocução Neutros no Corpus Paralelo The Adventures Of Huckleberry Finn - As Aventuras De Huck", de Daniel Alves e Adriana Pagano, utiliza um método com base em corpus paralelo para explorar padrões de escolha de verbos de elocução na textualização original e na (re)textualização de Monteiro Lobato da obra de Mark Twain, sobretudo aqueles relativos aos verbos de elocução neutros ('say', em inglês e 'dizer', em português).

Marcílio Garcia de Queiroga, e Lincoln P. Fernandes, em "Translation of children's literature" abordam a complexidade do exercício tradutório em literatura infantojuvenil. Os autores buscam 
definir o gênero, apontando as dificuldades e complexidades nessa definição e, apoiados em Peter Hunt, Ronald Jobe e Zohar Shavit, destacam as particularidades da tradução, entre as quais "a relação assimétrica/leitor dual em que o adulto se interpõe em todas as etapas que compõem a (tradução de) literatura infantojuvenil; a multiplicidade de funções, dado apontado pela inserção/pertencimento do gênero aos sistemas sócio-educacional e literário e permeado de valores por eles atribuídos; e a manipulação textual, percebida nas liberdades tomadas em virtude da condição periférica do gênero".

Maria Aparecida Barbosa, em seu artigo, explora a questão texto e imagem na tradução da obra Princesa Brambilla de E. T. A. Hoffmann. O conceito de "Nachleben" (sobrevivência), que pressupõe o resgate de imagens do passado, postulado pelo historiador de arte Aby Warburg em pesquisas sobre características de movimento da arte antiga nas imagens renascentistas de Botticelli, informa a análise de 8 gravuras cunhadas a partir de moldes originais de Callot (1820) ao português.

Em “L'oeuvre ouverte de Tomi Ungerer : traductions palimpsestes et transferts interculturels", Anne Schneider e Thérèse Willer analisam as traduções para o francês e o alemão do autor e ilustrador francês Tomi Ungerer que escrevia em inglês. Mostram a sua alsacianidade, o que cria um verdadeiro palimpsesto linguístico.

Em "Confúcio e o menino sem nome: intertextualidade e adaptação”, Márcia Schmaltz apresenta algumas reflexões a partir da pesquisa bibliográfica realizada para informar seu projeto conjunto de tradução com Sérgio Cappareli de narrativas chinesas para crianças. Com base na fundamentação teórica extraída dessa pesquisa, a autora discute suastomadas de decisão, levando em consideração os aspectos intrínsecos do texto de partida no sistema cultural chinês para sua transposição ao sistema da cultura brasileira.

Em "The Penitent Wag" e "The Funny-Man Who Repented": Discutindo Transposições do Conto "O Engraçado Arrependido" de Monteiro Lobato", Rosemary de Paula Leite Carter discute aspectos do cruzamento de duas traduções para o inglês americano (1925 e 1947) do conto "O engraçado arrependido", de 1923 de 
Monteiro Lobato. A autora aponta para a manipulação textual por parte dos tradutores que privilegiaram a cultura de chegada, o seja, a cultura do leitor das traduções em língua inglesa.

Muguras Constantinescu em "Traduire des contes pour les enfants: reflexions et pratiques" também demostra que as estratégias tradutórias são complementares às estratégias editoriais e pedagógicas na tradução de livros infantis. A partir dessa perspectiva, a autora concede um lugar particular ao paratexto que, segunda ela, satisfaz a curiosidade do jovem leitor e contribui ao desenvolvimento da sua competência enciclopédica. As análises de contos apresentadas pela autora exploram uma questão bastante atual e controversa na tradução de livros infantis e juvenis:a relação identidade/alteridade, abertura ao outro, ao diferente.

Em "A nova edição dos contos de Perrault: Regina Zilberman ressignifica Walcyr Carrasco”, Marcia Martins e Anna Olga Prudente de Oliveira analisam o trabalho de divulgação e valorização das traduções do contos de Perrault no Brasil no século XXI e se debruçam particularmente sobre o paratexto e a visibilidade do trabalho do tradutor/adaptador na tradução/adaptação realizada por Walcyr Carrasco, inicialmente publicada pela Editora Manole (2009) e agora em nova edição pela Editora Moderna (2013), com prefácio de Regina Zilberman.

Já na tradução do artigo "Explorando a diferença cultural através da tradução de literatura infantil" de Eva-Maria Metcalf e traduzido por Newton de Castro Pontes, apresenta-se um projeto aluno-professor em que os participantes traduziram um conto infantil do alemão para o inglês a fim de explorar o caráter cultural da linguagem e a natureza hermenêutica da tradução.

Por último, este volume apresenta duas resenhas e uma resenha de tradução, além de uma entrevista com Sergio Medeiros.

A resenha de Vanessa Hanes concerne ao volume Postcolonial polysystems: the production and reception of translated children's literature in South Africa, de Haidee Kruger que estuda a questão da tradução de literatura infantil na África do Sul a partir da interação dos Estudos da Recepção com os Estudos da Tradução. 
Lia Araujo Miranda de Lima resenha o livro Poetics of children's literature, de Zohar Shavit que fundou o ramo de estudos culturais referentes à infância e à juventude.

A resenha de tradução de autoria de Andréia Riconi e Davi S. Gonçalves oferece um resumo crítico sobre a recém tradução de Bela e a Fera, da escritora francesa Jeanne-Marie Leprince de Beaumont, com tradução inédita para o português de Marie-Hélène Torres e ilustrações de Laurent Cardon.

Já a entrevista, conduzida por Eliane Debus e concedida por Sérgio Medeiros, focaliza o fazer tradutório específico desse tradutor em relação a um dos títulos de Lewis Carrol pouco conhecido em língua portuguesa e intitulado Alice no Jardim de Infância, publicado pela editora Iluminuras em 2013.

As diversas abordagens teóricas, ideológicas, culturais, que vão do texto fonte ao texto alvo, mas também a análise de traduções da literatura infanto-juvenil enquanto produto, processo e função em seus respectivos contextos de produção e recepção, são algumas das principais questões abordadas neste número temático de Cadernos de Tradução. Boa leitura!

Eliane Santana Dias Debus Marie-Hélène Catherine Torres

Universidade Federal de Santa Catarina 